\title{
MINE SINKHOLE IN SICILY: GEOMORPHOLOGIC AND ENVIRONMENT
}

\section{HAZARD}

\author{
Vincenzo Liguori \& Giorgio Manno \\ Dipartimento di Ingegneria strutturale e Geotecnica, Facoltà di Ingegneria Palermo Sicily-(Italy). \\ e-mail:liguori@diseg.unipa.it
}

\begin{abstract}
The most complete Messinian evaporitic successions present in the Mediterranean can be found in Sicily. They are known as "Gessoso Solfifera Formation" and they widely emerge on the surface in the Sicilian central basin, Geologically known as " Caltanissetta Basin ", extending in direction NE-SW for around $140 \mathrm{Km}$, with a width of around $80 \mathrm{Km}$. Inside this area there are the Sicilian salty formations. The salt in these layers is white coloured and normally has an average grade in $\mathrm{NaCl}$ superior to $98 \%$, which is comparable to the best of such layers in the whole world. In some mines $\mathrm{KCl}$ salts are extracted. However, $\mathrm{NaCl}$ remains the mineral more abundant with stratigraphic thickness of several hundred meters. Given the remarkable mining importance of the products of the "Gessoso Solfifera Formation", in the central-southern Sicily, since the antiquity, different mining centres for the extraction of potassic salts and/or of rock salt have been developed and the greatest of them falls into the provinces of Enna, Caltanissetta and Agrigento. Among the many existing mines in the Sicilian territory at the moment, only two are active. All the others are disused and abandoned, sometimes without any control. For this reason and for the great solubility of this salt, the most feared events in these sites are: sinkholes and environmental pollution linked to the extraction procedures of the mineral. The mining basin of Racalmuto, classified as one of the greatest in Sicily, is a concrete example of the geomorphologic modifications of the territory linked with the presence of the mines that are now abandoned. In this area both halite and sylvite were extracted and the whole mining layer, given its dimensions, was separated in three sectors: a western (Mine of Racalmuto) a central, and an oriental (Mine of
\end{abstract} Montedoro).

The mines, built on more levels than one, had the typical structure of a gallery; chambers and pillars. The alkaline chlorides as sodium chloride $(\mathrm{NaCl})$ and potassium chloride $(\mathrm{KCl})$, suffer processes of dissolution because of the circulating waters which infiltrate the subsoil. The salts solubilisation has created a weakening of the hollow vaults of the mining tunnels producing, in extreme cases, sudden and local collapses that have involved the topographical surface (sinkholes), including in some cases, road and housing structures. The sinkholes, occurring in these areas, 
are often situated in correspondence with the meeting points of the mining galleries. They have almost always subcircular shapes and diameters varying in depth. At the moment, the mine of Racalmuto (western sector of the basin) in the layer of sub-emerging rock salt, shows an abyss of approximately $200 \mathrm{~m}$ in width and $40 \mathrm{~m}$ in depth. The mine was disused and finally abandoned because of the elevated depths of cultivation reached. The sinkhole occurred suddenly, swallowing the whole headgear of the well with some neighbouring buildings. The mine of Montedoro rises in an area where the covering grounds are clays that found the roof of the salty layer. The mining collapse in this case is produced by the missed covering of the well that has allowed the infiltration of the rainy waters inside the mine, destabilizing also the surrounding territory. Finally, in the central sector of the basin of Racalmuto there is another mine, disused for many years, and has in surface a large number of sinkholes resulting in critical instability of the area. The dimensions of the greatest sinkhole are approximately of $100 \mathrm{~m}$ in width and of $200 \mathrm{~m}$ in depth. The sinkholes currently individualized can be found in anthropic areas with road infrastructures and residences, and in sites used by man for cultivation and/or pasture. In many cases they are reasons for damages to houses and the activities that develop in the near areas. For this reason, the need for an accurate evaluation of the risk caused by this phenomenon, and a correct management programme of the territory are born.

Key Words: sinkholes, mines, Gessoso Solfifera Formation, evaporite dissolution.

\section{Mine sinkholes in Sicily}

In Sicily, Messinian evaporitic sedimentary deposits are developed under a wide variety of hypersaline conditions and in environments ranging from continental margin (subaerial), to basin-margin supratidal, to intertidal, to subtidal and out into the hyper-saline basin proper.

The topographic surface of the southern and the central side of Sicily is affected by depression and chasms, like the phenomena of sinkholes. The presence in the territory of these morphologies, closely linked to the collapses is highlighted through the analysis of aerial and satellite photographs performed with geological and geomorphological relief. The formation of chasms is almost always preceded by morphologies similar to the nature of karst dolines [1]. The appearance of the hill, is featured by localized depressions, (sub circular shaped, with diameters from 5 to $10 \mathrm{~m}$ and variable depth and size) at the bottom, at the centre of them depressed areas of preferential absorption can often be seen. The formation of these depressions causes inevitably changes of the flow of water in surface and underground circulating, the general hydrogeology changing of the area and sometimes it also modifies the stability 
of the closest areas. The depressions, during the winter, are usually full of water forming small lakes, while to the contrary, during the summer are completely dry. The sicilian sinkholes are mainly concentrated in the areas where the mining took place and their location is always depending on the development of the underground mine. In the southern and central side of Sicily there are a lot of mines, which once (1950-1960) were included among the most important european and extra-european producers of salts. Were born different mining centers for the extraction of potassium salts and / or rock salt, are present since antiquity and most of them are in the provinces of Enna, Caltanissetta and Agrigento. In Sicily, several of abandoned mines, have a rooms and pillars structure, the infiltrating inside waters weakens the pillars which stop supporting their actions, determining collapse phenomena and forming sinkholes. In other cases, sinkholes are linked to structural weaknesses of the mines tunnels. Commonly the location where sinkholes can occur, are the meeting points of tunnels where the distance between support elements is the longest. These influence the collapse of the vaults. The sinkholes in many cases are the cause of damage to buildings and relevant activities in neighbouring, so the need to evaluate the risk caused by these phenomena, increases for a correct management of the territory in the central and in the southern side of Sicily.

\section{Muti-Coffari: salts mine ( $\mathrm{NaCl}$ and $\mathrm{KCl})$}

The salt deposit is constituted from an asymmetrical fold with direction SW-NE and immersion SE, with maximum power of $100 \mathrm{~m}$. The cultivation method was cultivation with pillars. In this way overlapping galleries were obtained and rooms supported from salts pillars. The infiltration of waters in the subsoil has produced salts dissolution operating a fall of the vaults and a weakening of the pillars of the tunnels. The incessant action of waters in the mine has determined the fall of the vaults of the tunnels, interesting the topographical surface and generating sinkholes

[2]. . The most important sink has originated from the fall of the vault of level 0 of the mine (the nearest to topographical surface) that involved also the below levels 1 and 2 . The fall of the vaults of the tunnel has originated sinkhole that involved a volume of material of $8000 \mathrm{~m}^{3}$ and created a sink deep $30 \mathrm{~m}$. Currently the sinkhole is filled up with the land that slowly continues to slide down from the near versant. Other small sinkholes are created in other areas over the mine. There are complex landslides that created numerous depressions. In the considered areas there are a lot of smalls lakes generated from the formation of small sinkholes, that have been completely filled from argillaceous lands present in the territory. The meteoric waters that continue to enter from the sinks in surface, store in the underground cavities, where they continue their incessant action of dissolution of salts. In the periods of 
greater rainfall the present waters inside the mine, are infiltrated from the sinkholes, increasing their level until exiting from the old income, flowing to in Platani's river by a small affluent. The entire ecosystem of the river Platani is modified, generating a great negative impact. Currently the evolution of the phenomenon is being studied analyzing the natural and anthropic causes that determine the sinkholes risk, in order to be able to take part in naturalistic methods to the safeguard of the Platani ecosystem (chemical pollution) and the evolution geomorphologic area [3].
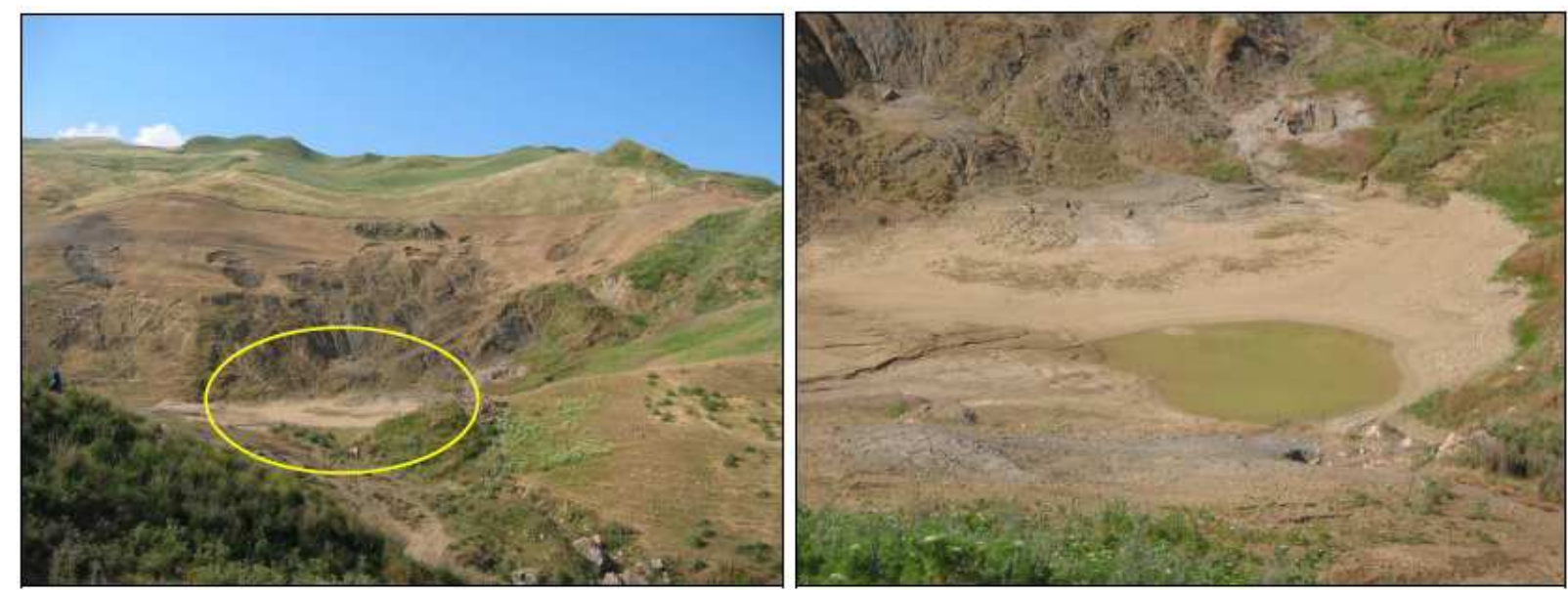

Figure 1: Muti Coffari Sinkhole

\section{Racalmuto: gessoso-solfifero basin (Caltanissetta)}

The mining area of Racalmuto-Montedoro was classified as a reservoir medium - large, with maximum depth of $1000 \mathrm{~m}$. The minerals extracted are halite $(\mathrm{NaCl})$ and sylvite $(\mathrm{KCl})$. The large ground for simplicity was divided into three sectors:

1) Western sector (Vallone Racalmuto); was affected by numerous quarries of salt rock ( $\mathrm{NaCl}$ and $\mathrm{KCl})$ because the mineral is outcrop.

2) Central sector (Sacchitello-Pantano-Racalmuto); were mined exclusively potassium salts.

3) Eastern sector (Contrada Marchesa - Montedoro); were mined halite and potassium salts. The cover ground between the central and eastern area is a very permeable soil, while that in the eastern sector towards the town Montedoro is a low permeable soil as the cover ground. It is composed of alternating clays, chalks (Miocene) and marls (“trubi”- early Pliocene).

\subsection{Montedoro mine - Salts mine ( $\mathrm{NaCl}$ and $\mathrm{KCl})$}


The cover ground consists of alternation of clays, gypsums (Miocene) and marls ("trubi" early Pliocene). The sinkhole found at the site of mining interests Montedoro a Kainite well, and the collapse was generated from the non-coating well. When collapsed the well the cone landslide has also involved a building adjacent, whose function was to winch room. The sinkhole has a diameter of about $24 \mathrm{~m}$ and a depth of about $30 \mathrm{~m}$, it was reactivated in time several times but has now ceased its development.The ex-miners tell that for fell the well, following the collapse, there was the intetention of used forty trucks containing mining discarded (rosticci). Fortunately this material has never been used since the well was closed only through the rockfall of gypsum rock of different sizes. For the village area, the area appears rather degraded by the time the buildings adjacent the sinkhole were used at table, offices, direction and a residential village. The remarkable inclination suffered from the structure was produced mixed-out of a platform in order to confine a fence through the area at risk.
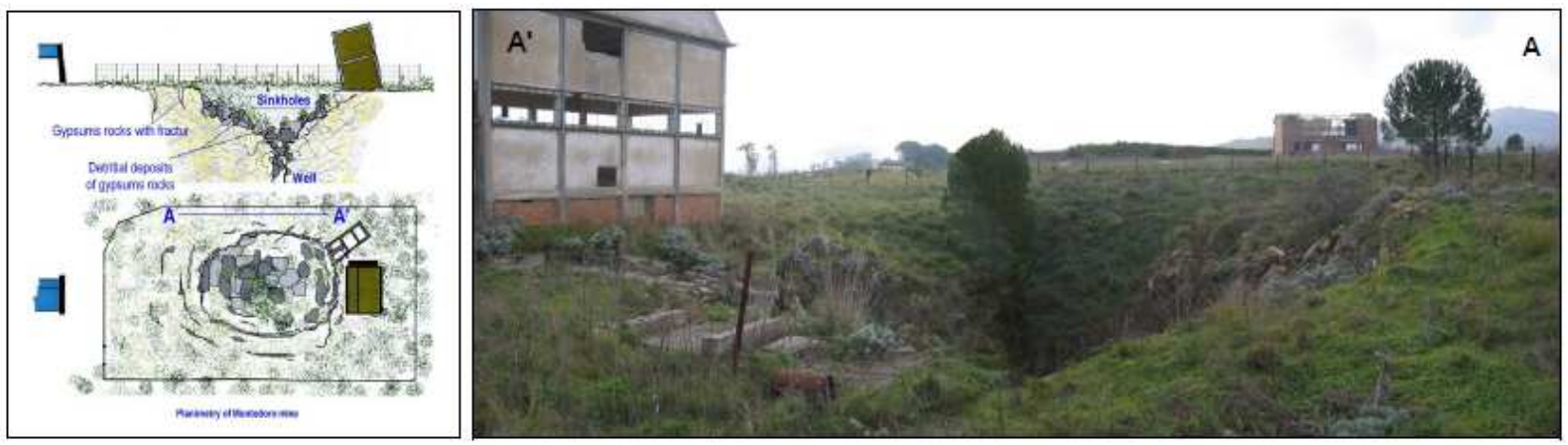

Figure 2: Sinkhole in Montedoro mine

\subsection{Racalmuto mine - ISPEA (Caltanissetta)}

The Racalmuto mine of halite and potassium salts is on an area characterized by outcrop rocks salts. The unit mining Racalmuto ISPEA upon cessation of the activity (1990), was still potentially exploitation. Infact in 1990 the mining structure were and intact and functioning. When the mine is being retired, because of the high depth of cultivation of halogen mineral have triggered processes infiltration by rain water. The rain water not be extracted from the mine for the failure of the well 2, located 300m of deep. The infiltration of rain water, with the consequent dissolution of salts in the mine, formed the sinkhole. This involving in topographic surface and the presents infrastructures. For example, the metallic castle, about $40 \mathrm{~m}$ high, which was used by the mine hoists, has been completely swallowed by the abyss. For nearly five years, the sinkhole is stable and is currently about $200 \mathrm{~m}$ wide and about $50 \mathrm{~m}$ deep. The area affected by the sinkhole was safety through two fences for to prevent the access to any passers-by. 


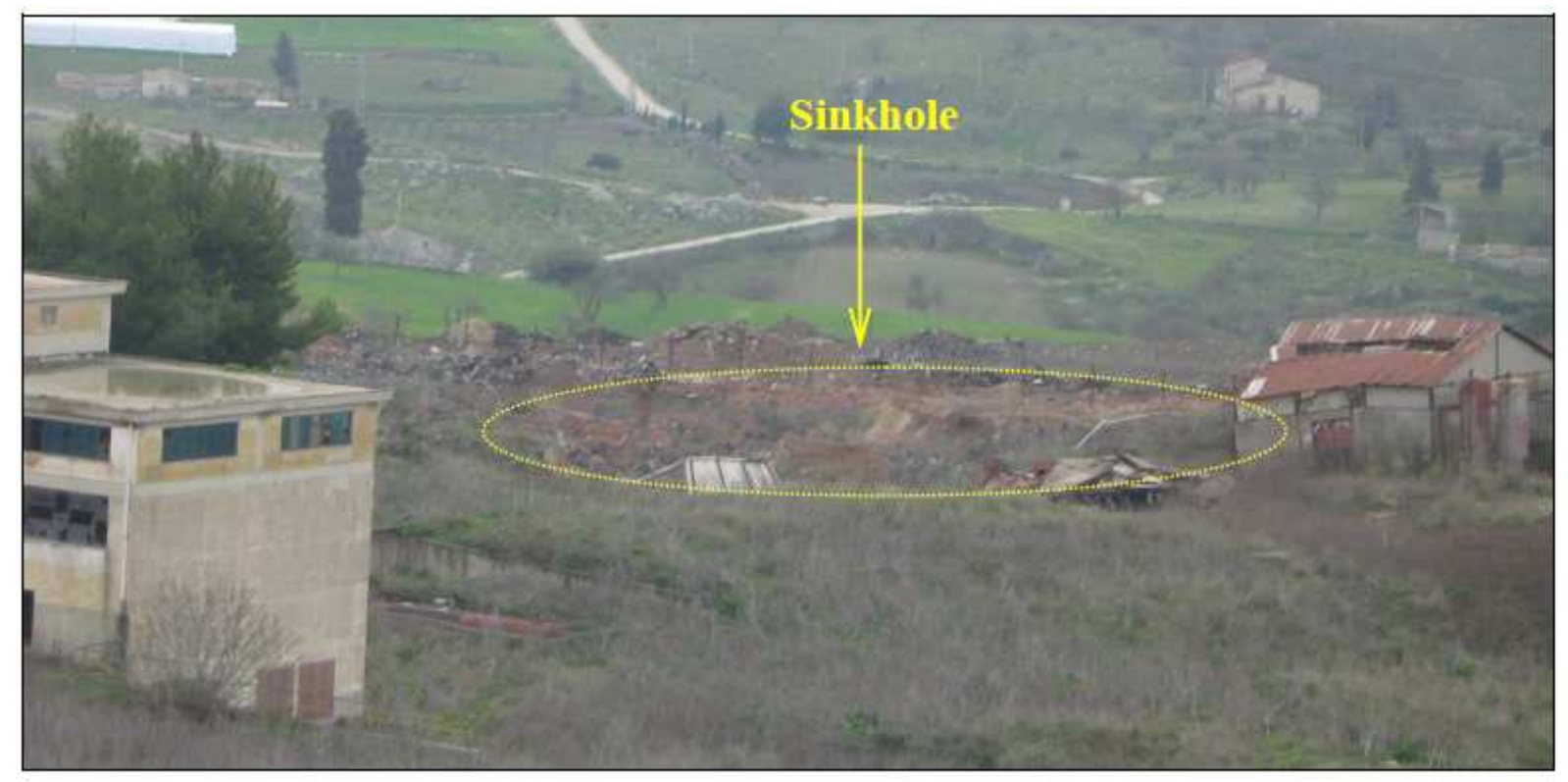

Figure 3: Sinkhole ISPEA mine

\subsection{Racalmuto mine - ITALKALI (Caltanissetta)}

The Racalmuto mining area of managed by the company ITALKALI has two mines, one active, which have not been reported sinkholes, and a disused, whose closure was launched due to collapse in the mine area near the entrance. The sinkholes are far-reaching and affect most of the cover ground of the mine. The cover ground is constituted of intercalation of gypsum and clay. Among the several sinkholes found the larger has a width of approximately of $200 \mathrm{~m}$ and a depth of approximately of $28 \mathrm{~m}$.

\subsection{Racalmuto mine (Contrda Pantanelli)}

The mine was a mine operated by private, is located in Contrada Pantanelli and falls in the central sector of the ground salt Montedoro-Racalmuto. From surveys carried out in this location it was found that the whole body rocky coverage of the mine is subject to collapse [4], numerous sinkholes have been identified, but the larger sinkhole has a width approximately of $100 \mathrm{~m}$ and a depth not great easily found because no one can distinguish the bottom of the sinkhole. From the pictures it can be said that the depth is not less $80 \mathrm{~m}$. 

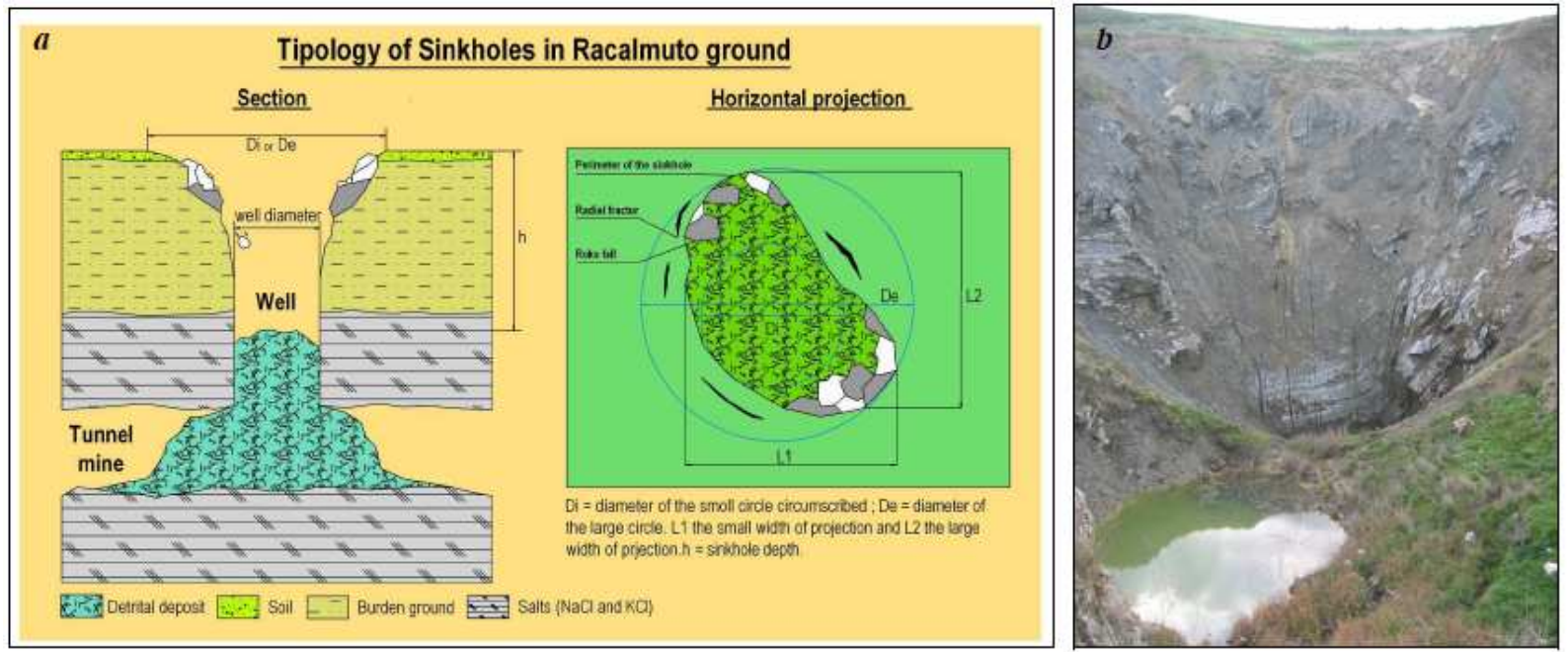

Figure 4a) tipology of sinkhole. 4b) sinkhole in Contrada Pantanelli

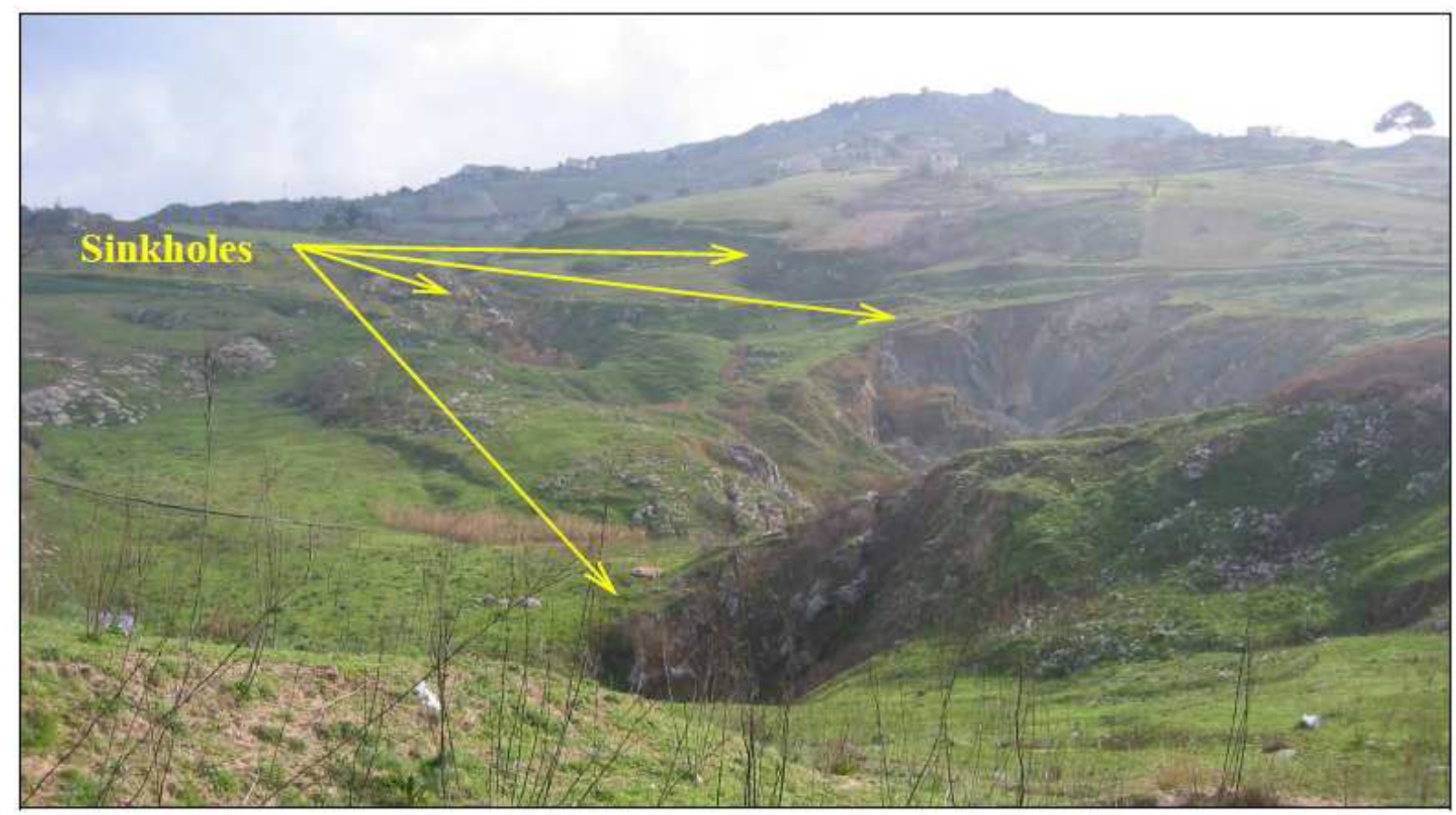

Figure 5: different sinkholes in Contrada Pantanelli

\section{Cattolica Eraclea mine - (Agrigento)}

The ground salt of Catholica Eraclea is a basin with average depths of salt deposit of between 0 and $500 \mathrm{~m}$. The halite mine is located at SE of the country Cattolica Eraclea (Agrigento), the ground salt stretches $1 \mathrm{~km}$ wide and $2 \mathrm{~km}$ in length. The land cover are low-permeable, those at bed of impermeable, because the salt is confined between layers of clay and gypsums of different thickness. The mine was closed due to a collapse, which fortunately did not 
result in serious damage in terms of loss of life since the fall was registered during the night, then there were mine workers. The sinkholes are clearly visible both at the mine is on the coverage area, those present at the entrance of the mine size of the order of several meters, while those affecting land roof are much larger, with a average width approximately $80 \mathrm{~m}$ and a depth of about $24 \mathrm{~m}$. In this area are surveyed 10 sinkholes, in particular the following characteristics:
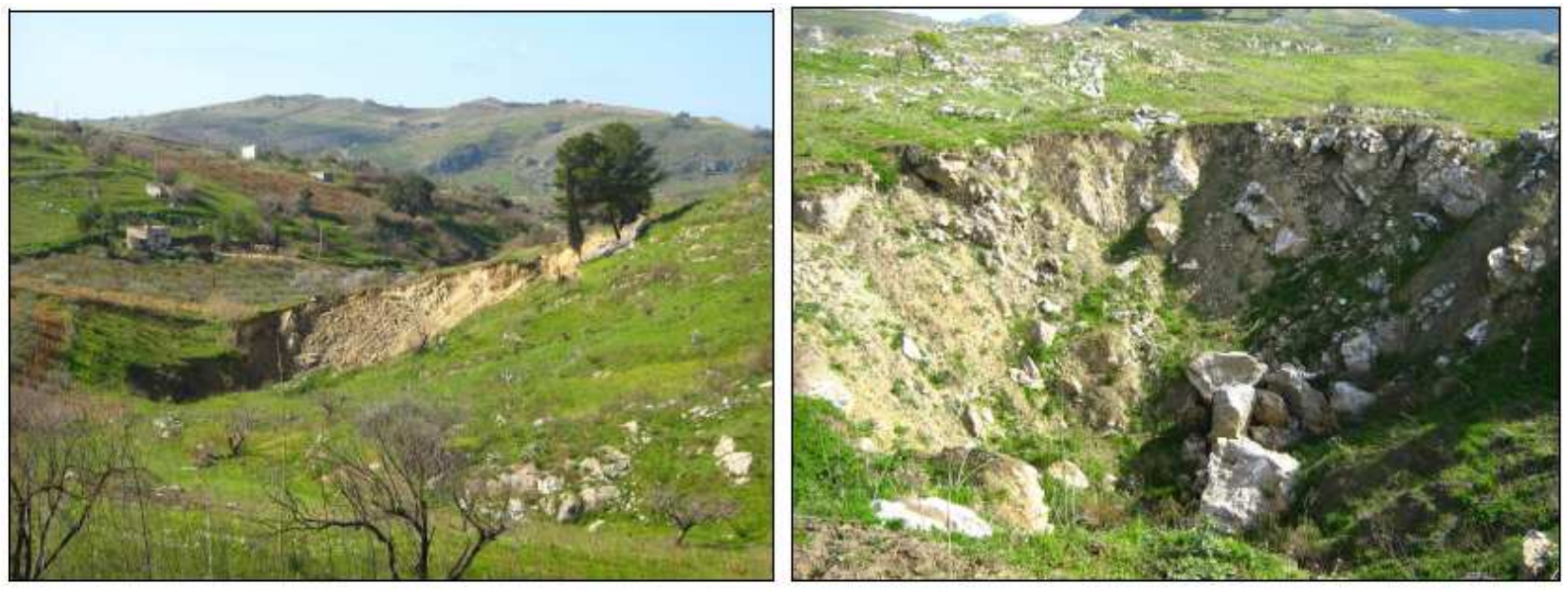

Figure 6: Sinkholes in Cattolica Eraclea mine

\section{Reference}

1. F. Gutierrez, A.H. Cooper, K. S. Jhonson (2008). Identification, prediction, and mitigation of sinkhole hazards in evaporite karst areas in Environ. Geol. vol. 53 pp. 1007-1022.

2. P. Lucha, F. Gitierrez and J Guerrero (2008). Environmental problems and geological implications derived from evaporite dissolution in the Barbastro salt anticline (NE Spain), in Environ. Geol. vol. 53 pp. 10451055

3. V. Liguori, G. Manno and D. Mortellaro (2008). Evaporite Karst in Sicily in Environ. Geol. vol. 53 pp. 975-980. Springer

4. F. Gutierrez, J Guerrero and P. Lucha (2008). A genetic classification of sinkholes illustrated from evaporite paleokarst exposures in Spain, in Environ. Geol. vol. 53 pp.993-1006. Springer 
